\title{
Acceptability and utilization of a lipid- based nutrient supplement formulated for pregnant women in rural Niger: a multi- methods study
}

Sheila Isanaka ${ }^{1,2^{*}}$, Stephen R. Kodish², Abdoul Aziz Mamaty ${ }^{3}$, Ousmane Guindo ${ }^{3}$, Mamane Zeilani ${ }^{4}$ and Rebecca F. Grais ${ }^{1}$

\begin{abstract}
Background: In food insecure settings, it may be difficult for pregnant women to meet increased nutritional needs through traditional diets. A promising new strategy to fill nutrient gaps in pregnancy involves the provision of lipidbased nutrient supplements (LNS). We aimed to assess the acceptability and utilization of a $40 \mathrm{~g}$ LNS formulation (Epi-E) with increased micronutrient content relative to the recommended daily allowance among pregnant women in rural Niger.

Methods: We conducted a two-part, multi-methods study among pregnant women presenting to antenatal care in Madarounfa, Niger during two periods (Ramadan and non-Ramadan). Part 1 included two LNS test meals provided at the health center, and Part 2 included a 14-day home trial to simulate more realistic conditions outside of the health center. Open- and closed-ended questions were used to assess organoleptic properties of Epi-E using a 5-point hedonic scale after the test meals, as well as utilization and willingness to pay for Epi-E after the 14-day home trial.

Results: Participants consumed more than $90 \%$ of the test meal in both periods. Epi-E was rated highly in terms of overall liking, color, taste and smell during test meals in both periods (median 5/5 for all); only time, mode and frequency of consumption varied between Ramadan and non-Ramadan periods in observance of daily fasting during the holy month.

Conclusion: Epi- E, a $40 \mathrm{~g}$ LNS formulation with increased micronutrient content, was highly acceptable among pregnant women in rural Niger, and utilization was guided by household and individual considerations that varied by time period. This formulation can be further tested as a potential strategy to improve the nutritional status of pregnant women in this context.
\end{abstract}

Trial registration: ClinicalTrials.gov Identifier: NCT02145000. Registered 22 May 2014.

Keywords: Acceptability, Utilization, Pregnant women, Lipid-based nutrient supplement (LNS), Hedonic scale, Readyto-use food

\footnotetext{
* Correspondence: sheila.isanaka@epicentre.msf.org

${ }^{1}$ Epicentre, 8 rue Saint Sabin, 75011 Paris, France

${ }^{2}$ Harvard T.H. Chan School of Public Health, 665 Huntington Ave, Boston, MA

02115, USA

Full list of author information is available at the end of the article
}

(c) The Author(s). 2019 Open Access This article is distributed under the terms of the Creative Commons Attribution 4.0 International License (http://creativecommons.org/licenses/by/4.0/), which permits unrestricted use, distribution, and reproduction in any medium, provided you give appropriate credit to the original author(s) and the source, provide a link to the Creative Commons license, and indicate if changes were made. The Creative Commons Public Domain Dedication waiver (http://creativecommons.org/publicdomain/zero/1.0/) applies to the data made available in this article, unless otherwise stated. 


\section{Background}

Nutrient requirements are increased during pregnancy and essential to meet the needs of both the developing fetus and mother. In resource-poor settings with poor food availability or limited dietary quality, it may be difficult for pregnant women to meet optimal nutrient intake through traditional diets alone [1]. Sub-optimal nutrient intake during pregnancy can contribute to adverse pregnancy outcomes, including increased maternal and neonatal mortality, as well as long-term developmental impairment for the child [2-4].

Several strategies are recommended to help meet the higher nutritional requirements during pregnancy, including iron folic acid (IFA) and multiple micronutrient (MMN) supplementation [5]. IFA supplementation alone can reduce anemia and iron-deficiency anemia at term, but is associated with adverse effects from high doses of iron and low compliance [6]. MMN supplementation with IFA has been shown to have positive impacts on neonatal health outcomes, including reduced risk of small-forgestational age, low birthweight, and stillbirth [7].

Recent evidence suggests that combining MMN with both energy and protein may improve birth outcomes compared to MMN or IFA alone [8, 9]. Therefore, a promising new strategy to meet the nutritional needs in pregnancy involves the provision of lipid-based nutrient supplements (LNS). LNS are micronutrient-rich pastes that are often made of peanuts, oil, sugar and milk powder and require no preparation or refrigeration during home use. First developed in large-quantities (92 g) at therapeutic doses for the treatment of severe acute malnutrition, LNS can also be provided in smaller quantities to meet specific nutrient gaps [10]. The first evidence for LNS use among pregnant women in Ghana and Malawi suggest that a small-quantity dosage (20 g) may be acceptable in these populations $[11,12]$.

The current study builds on this limited experience by reporting on the acceptability and utilization of LNS among pregnant women in rural Niger. We aimed to assess a $40 \mathrm{~g}$ LNS formulation with increased micronutrient content before testing effectiveness in terms of maternal and child health outcomes. Despite the larger dose and increased micronutrient content, we hypothesized that the $40 \mathrm{~g}$ LNS would be both acceptable and appropriately utilized among pregnant women in Niger given previous experience with LNS among children in this context and general palatability of the new formulation.

\section{Methods}

\section{Parent trial}

In 2012, a phase III randomized, double-blind, placebocontrolled trial to test the efficacy of the bovine rotaviruspentavalent vaccine (BRV-PV) began in Madarounfa, Niger (ClinicalTrials.gov Identifier: NCT02145000). Details of the parent trial and study setting have been published elsewhere [13]. In recognition of the need to identify potential boosters of immunogenicity in countries where oral vaccine efficacy is low, a cluster randomized sub-study was designed to identify complementary interventions that may increase vaccine efficacy. One potential mechanism hypothesized to underlie lower immunogenicity observed in some settings is related to the inhibitory effects of poor nutrition on immune development [14]. The role of nutrition in immune development has been reasonably well documented in observational studies, where both macro- and micronutrient deficiencies have been shown to result in the impairment of various components of the immune system [15]. There is also evidence that micronutrient, fatty acid and protein-energy nutrition in early life may play a role in immune development $[16,17]$, but there have been few randomized studies to evaluate the impact of early nutritional intervention on infant immune development. We therefore proposed to evaluate the effect of prenatal nutrition supplementation on infant immune response as a nutritionimmunogenicity sub-study; the sub-study specifically aimed to test whether daily prenatal nutritional supplementation with LNS or MMN improves infant immune response to three doses of oral vaccine, compared to IFA.

\section{LNS formulation}

A new, 40-g LNS formulation (hereafter referred to as 'Epi-E') was developed in collaboration with Nutriset SAS (Malaunay, France) to meet the nutritional needs of pregnant women in rural Niger. It is a modified form of the 20-g LNS developed by the iLiNS Project for supplementation of pregnant and lactating women in Ghana and Malawi [18]. The Epi-E dose was increased from 20 $\mathrm{g}$ to $40 \mathrm{~g}$ based on findings from Burkina Faso where a higher dose prenatal MMN-fortified food supplement was shown to increase birth length compared to MMN supplementation alone [8]. Epi-E includes iron and folic acid and provides approximately two times the United States Institute of Medicine recommended daily allowance (RDA) of several micronutrients, including twice the recommended amounts of vitamin B complex, zinc, and selenium levels recommended for pregnant women [19] (Table 1). Phosphorus, potassium, magnesium, and calcium levels were provided at the highest levels possible given constraints of taste profile and stability.

\section{Recruitment and inclusion criteria}

This study was conducted in Madarounfa, a rural department in the Maradi region of Niger. The department comprises several communes, one of which comprises the urban area of Madarounfa. Recruitment took place in June (Ramadan) and again in September (non-Ramadan) 2014 among women presenting for routine antenatal care visits at one study health center. Women at 
Table 1 Nutrient composition of Epi-E lipid-based nutrient supplement

\begin{tabular}{|c|c|c|}
\hline Nutrient & $\begin{array}{l}\text { United States Institute of Medicine Recommended Dietary } \\
\text { Allowance (RDA) for Pregnant Women aged 19-30 years }{ }^{18}\end{array}$ & $\begin{array}{l}\text { Epi-E }{ }^{\mathrm{a}} \text { LNS ( } 40 \mathrm{~g} \text { daily dose) for } \\
\text { Pregnant Women }\end{array}$ \\
\hline Energy (kcal) & - & 237 \\
\hline Proteins (g) & 71 & 5.2 \\
\hline Lipids (g) & ND & 20 \\
\hline LA (Linoleic Acid) (g) & $13^{*}$ & 6.9 \\
\hline ALA (a-Linolenic Acid) (g) & $1.4^{*}$ & 1.16 \\
\hline Calcium (mg) & 1000 & 559 \\
\hline Phosphorus (free) (mg) & 700 & 400 \\
\hline Potassium (mg) & $4700^{*}$ & 400 \\
\hline Magnesium (mg) & 350 & 130 \\
\hline Zinc (mg) & 11 & 30 \\
\hline Copper (mg) & 1 & 4 \\
\hline Iron (mg) & 27 & 30 \\
\hline Manganese (mg) & 2 & 2.6 \\
\hline lodine $(\mu \mathrm{g})$ & 220 & 250 \\
\hline Selenium $(\mu \mathrm{g})$ & 60 & 130 \\
\hline Vitamin A $(\mu \mathrm{g})$ & 770 & 800 \\
\hline Vitamin $B_{1}(\mathrm{mg})$ & 1.4 & 2.8 \\
\hline Vitamin $B_{2}$ (mg) & 1.4 & 2.8 \\
\hline Niacin (mg) & 18 & 36 \\
\hline Pantothenic acid (mg) & 6 & 7 \\
\hline Vitamin $B_{6}(\mathrm{mg})$ & 1.9 & 3.8 \\
\hline Folic acid $(\mu \mathrm{g})$ & 600 & 400 \\
\hline Vitamin $B_{12}(\mu \mathrm{g})$ & 2.6 & 5.2 \\
\hline Vitamin C (mg) & 85 & 100 \\
\hline Vitamin $D_{3}(\mu \mathrm{g})$ & 15 & 15 \\
\hline Vitamin E (mg) & 15 & 20 \\
\hline Vitamin $K_{1}(\mu \mathrm{g})$ & 90 & 45 \\
\hline
\end{tabular}

Ingredients list: Non hydrogenated vegetable fat, skimmed milk powder, peanuts, defatted soy flour, sugar, maltodextrin, vitamin and mineral complex, stabilizer: hydrogenated vegetable fat, emulsifier: vegetable lecithin (soy or sunflower), antioxidant

*Adequate intake (Al) reported; everything else presents Recommended Daily Allowance (RDA)

least 18 years of age with a confirmed pregnancy were eligible to participate. Women were excluded if they had a known intolerance to milk or peanuts, or their clinical status at the time of evaluation required inpatient referral. Women who met the inclusion criteria and did not fit the exclusion criteria were given oral and written details of the study and asked to sign or thumbprint the printed informed consent form. After providing consent, participating women were asked to return to the health center the following day. Gestational age of participants was not assessed at the time of enrollment.

\section{Study design and procedures}

This study collected data during two calendar periods: June (Ramadan) and September (non-Ramadan) 2014. Ramadan is the Muslim holy month marked by daily fasting from sunrise to sunset. Pregnant women may be exempt from daily fasting, however household practices may influence individual food preparation and intake during this period. In Niger, where more than $98 \%$ of population is estimated to practice Islam, this design allowed for a description of Epi-E acceptability and utilization during two important periods when dietary intake and practices are very different for the majority of the population. In both time periods, a two-part, multimethods study design was used among two independent samples of participants.

Part I was designed to evaluate Epi-E acceptability through repeated observation of two test meals provided at the health center. Prior to each test meal, trained study staff collected morbidity information from each participant using a self-report of the previous $24 \mathrm{~h}$. Study 
staff combined Epi-E and locally-purchased ingredients into a fermented maize porridge mixture in a 1:4 ratio. Maize porridge was used in the test meal as it is a common, staple-food preparation available to and often consumed by pregnant women in this context. Each study participant was individually given $50 \mathrm{~g}$ of the Epi-E/ maize porridge mixture while being observed by a trained interviewer outside of the health center. This amount represented $10 \mathrm{~g}$ of Epi-E (approximately two teaspoons) and $40 \mathrm{~g}$ of maize porridge (approximately 2-3 tablespoons).

Interviewers weighed the amount of Epi-E/maize porridge mixture that each participant was served and the amount remaining after $15 \mathrm{~min}$. The portion consumed was defined as the difference between the starting and ending volume to the nearest gram. After the test meal, the interviewer asked each participant to rate the characteristics of the Epi-E/maize porridge mixture based on her perceptions of its organoleptic properties, including color, odor, taste, and overall liking, using a hedonic scale with 5 options $(1=$ Dislike a lot, $2=$ Dislike a little; $3=$ Neither like nor dislike; $4=$ Like a little; $5=$ Like a lot). The 5-point scale was visually depicted using a range of emoticon faces (very unhappy to very happy) that have been previously used to measure food acceptability in illiterate populations [20-22]. Participants were also asked open-ended questions for further explanations and clarifications. The test meal was repeated on two consecutive days to allow women to habituate to the procedures and as a strategy to reduce influence of observation on behaviors.

Part II followed Part I and was designed to simulate more realistic conditions outside of the health center by including a home-feeding trial where participants received a take-home ration of Epi-E to use. A one-day supply of Epi-E included one $40 \mathrm{~g}$ sachet to be divided into two meals. Each participant was given a 14-day supply; in the first home trial conducted in June, participants were provided two additional sachets (16 total) in consideration of potential sharing (e.g. distribution of Epi-E among individuals other than the intended beneficiary, including children and other adults within and outside of the household). Participants received oral instructions regarding the appropriate daily dose of Epi-E for consumption, proper storage at room temperature, and the importance of adding it to a meal only after the cooking process.

After completion of the 14-day study period, participants were invited to return to the health center. To estimate compliance, study staff recorded the number of unused sachets returned to the health center with each participant and asked each woman how many sachets were either consumed by the participant or shared with other individuals. A post-trial questionnaire, with both close- and open-ended questions was administered to further assess the incidence of adverse events (e.g. diarrhea, vomiting, fever, reduced appetite, and constipation), as well as the quantity, timing and mode of consumption of Epi-E during the 14-day home trial. In September, interviewers additionally asked participants about their perceptions of Epi-E properties using a hedonic scale, as well as their willingness to use Epi-E again and pay for it in the future after the home trial period. All interviewers provided textual field notes regarding their perception of the product acceptability for further triangulation of data from the interviewers' perspective.

A sample size of 25 women provided more than $90 \%$ power to test the hypothesis that mean consumption in Part 1 was at least $50 \%$ of the Epi-E/maize porridge mixture offered, assuming a standard deviation (SD) of consumption of $30 \%$ of the amount offered and a true mean of $75 \%$.

\section{Data analysis}

Participant characteristics, including socio-demographic characteristics and self-reported morbidity, as well as results from the Part 1 test meals and Part 2 home trial were summarized using means (SD) for continuous measures, and using counts and proportions for discrete measures. A one-sample t-test was used to assess the difference between the hypothesized and observed mean consumption [23]. Hedonic scale responses rating sensory properties were presented as medians (min, max). Textual responses generated from the open-ended questions underwent an inductive review to identify thematic areas [24]. We considered both their frequency of mention and importance relative to the study aims when deeming emergent themes to be salient. Exemplar quotations were presented in text to illustrate key findings and as corroboration of quantitative results [25, 26]. All quantitative data were double-entered into an EpiData 3.1 database (EpiData, Odense, Denmark) and analyzed using Microsoft 2010 Excel (Microsoft, Redmond, Washington).

This study was conducted according to the guidelines laid down in the Declaration of Helsinki and all procedures involving human subjects/patients were approved by the National Consultative Ethics Committee of Niger, as well as the Western Institutional Review Board. Written informed consent was obtained from all participants.

\section{Results}

Characteristics of participating women are presented in Table 2. Mean (SD) age was 29.5 (7.5) years in June (Ramadan) and 27.9 (7.8) years in September (non-Ramadan), with women reporting a mean of approximately 5 previous pregnancies in both time periods. Very little 
Table 2 Baseline characteristics and health of participants by day of test meal

\begin{tabular}{|c|c|c|c|c|}
\hline \multirow[t]{2}{*}{ Test day, $(n)$} & \multicolumn{2}{|c|}{ June 2014 (Ramadan) } & \multicolumn{2}{|c|}{ September 2014 (non-Ramadan) } \\
\hline & Day 1 (26) & Day 2 (26) & Day 1 (28) & Day 2 (27) \\
\hline \multicolumn{5}{|l|}{ Participant characteristics } \\
\hline Age, Mean (SD) & $29.5(7.5)$ & & $27.9(7.8)$ & $27.7(7.8)$ \\
\hline Previous pregnancies, Mean (SD) & $5.5(2.9)$ & & $5.3(3.2)$ & $5.2(3.1)$ \\
\hline \multicolumn{5}{|l|}{ Reported Illness in previous 24 h, $n$ (\%) } \\
\hline Runny nose & $0(0.0)$ & $0(0.0)$ & $1(3.6)$ & $1(3.7)$ \\
\hline Cough & $4(15.4)$ & $3(11.5)$ & $3(10.7)$ & $1(3.7)$ \\
\hline Difficulty breathing & $0(0.0)$ & $0(0.0)$ & $0(0.0)$ & $0(0.0)$ \\
\hline Diarrhea & $0(0.0)$ & $0(0.0)$ & $0(0.0)$ & $0(0.0)$ \\
\hline Fever & $0(0.0)$ & $0(0.0)$ & $0(0.0)$ & $0(0.0)$ \\
\hline Vomiting/nausea & $1(3.8)$ & $0(0.0)$ & $0(0.0)$ & $0(0.0)$ \\
\hline Ear infection & $0(0.0)$ & $0(0.0)$ & $0(0.0)$ & $0(0.0)$ \\
\hline Other ${ }^{\mathrm{a}}$ & $0(0.0)$ & $0(0.0)$ & $2(7.1)$ & $0(0.0)$ \\
\hline Usual appetite on test day, $n$ (\%) & $26(100.0)$ & $26(100.0)$ & $28(100.0)$ & $27(100.0)$ \\
\hline
\end{tabular}

${ }^{\mathrm{a} O t h e r ~ i l l n e s s e s ~ r e p o r t e d ~ o n ~ D a y ~} 1$ (September 2014) were anemia $(n=1)$ and cold $(n=1)$

illness was reported in the $24 \mathrm{~h}$ before any test meal, and all participants reported having usual appetites.

\section{Test meal results}

There was no meaningful variation in results between days (day 1 vs. day 2) or between time periods (June (Ramadan) vs. September (non-Ramadan)). Participants consumed more than 95 and $90 \%$ of the $50 \mathrm{~g}$ serving provided in under two minutes in June (Ramadan) and September (non-Ramadan), respectively (Table 3). Mean consumption during both test meals was significantly greater than the null hypothesis of $50 \%$ consumption $(p<0.05)$. After both test meals, the Epi-E mixture was rated highly, with median responses of ' $5=$ Like a lot' in terms of overall liking, color, taste and smell. Participants assigned no score lower than ' $4=$ Like a little' to any single category of the hedonic scale. Interviewers also perceived all participants to enjoy Epi-E, noting that women were "happy and ready to continue using Epi-E" after the meal.

\section{4-day home trial results}

Participants reported consuming a mean of 14 sachets as prescribed. The mean (SD) number of sachets consumed per day by participants were, however, observed to be higher in June (Ramadan) than in September (nonRamadan) (1.7 (0.5) sachets/day vs. 1.1 (0.3) sachets/day) (Table 4). These results indicate that not all participants ate exactly 1 sachet per day over the 14-day trial period as prescribed, but all sachets were used and none were reported sold or traded. When probed as to why they consumed the quantity of LNS they did, women in both study periods most frequently reported taking 1 sachet/ day in order to "respect the prescribed dosage" or because it was "the instructions that I received" or "advice I was given," indicating the potential for high compliance with a prescribed dosing with instructions. The only side effects reported were during June (Ramadan) and included 1 case of fever (3.8\%) and 1 case of other ("change in urine color") (3.8\%).

In June (Ramadan), 72\% of women ate half of one sachet at each serving, with servings most often taken in the morning and again later in the evening. By contrast, in September (non-Ramadan), women more often ate one full sachet each day, in either the morning (60.0\%) or midday $(40.0 \%)$, but never in the evening. Follow-up questions revealed that the preferred time of consumption was dependent on individual-level factors. Participants in both periods indicated that they were "hungrier" or had "big appetites" in the morning. Others chose when to eat Epi-E based on practical reasons related to work schedules and convenience. One person explained that she specifically chose to eat Epi-E at specific times, "to keep children from seeing [her eating it]." During June (Ramadan), participants reported consuming Epi-E early in the morning and/or around dinner or evening time, invoking dietary practices during the holy month for these preferred times, "Because of the fast, I prefer to take it [Epi-E] at dawn and after dinner." In both time periods, Epi-E was almost universally consumed directly from the sachet. The most commonly reported reason for doing so was based on flavor. Many women said that they "like the taste alone, without the mixture". Another salient theme was the notion that eating out of the sachet represented "direct" consumption, which was explained by participants to be both "good" and "better" than mixing. Women also cited convenience for using this mode of consumption. 
Table 3 Consumption behaviors and attitudes toward Epi-E on day of test meal

\begin{tabular}{|c|c|c|c|c|}
\hline & \multicolumn{2}{|c|}{ June 2014 (Ramadan) } & \multicolumn{2}{|c|}{ September 2014 (non-Ramadan) } \\
\hline & Day 1 & Day 2 & Day 1 & Day 2 \\
\hline No. of participants, $n$ & 26 & 26 & 28 & 27 \\
\hline \multicolumn{5}{|l|}{ Consumption of $50 \mathrm{~g}$ Epi-E/maize porridge mixture } \\
\hline Grams of serving consumed, Mean (SD) & $48.56(1.50)$ & $47.60(2.18)$ & $45.64(1.83)$ & $45.78(1.99)$ \\
\hline Average amount consumed of total serving, (\%) & 97.12 & 95.20 & 91.28 & 91.56 \\
\hline Time (min) taken to consume, Mean (SD) & $1.73(0.96)$ & $1.08(0.39)$ & $1.54(0.88)$ & $1.00(0.68)$ \\
\hline \multicolumn{5}{|l|}{ Hedonic scale scores of Epi-E, median (min, max) ${ }^{a}$} \\
\hline Overall liking & $5(5,5)$ & $5(5,5)$ & $5(4,5)$ & $5(5,5)$ \\
\hline Color & $5(5,5)$ & $5(5,5)$ & $5(4,5)$ & $5(5,5)$ \\
\hline Taste & $5(5,5)$ & $5(5,5)$ & $5(4,5)$ & $5(5,5)$ \\
\hline Smell & $5(5,5)$ & $5(5,5)$ & $5(4,5)$ & $5(5,5)$ \\
\hline \multicolumn{5}{|l|}{ Interviewer perceptions, n (\%) } \\
\hline Interviewer believes participant liked Epi-E & $26(100.0)$ & $26(100.0)$ & $27(96.42)$ & $27(100.0)$ \\
\hline
\end{tabular}

${ }^{\mathrm{a}}$ Response values ranged from 1 (Dislike a lot) to 5 (Like a lot)

All women in the post-trial assessment reported positive feelings toward the supplement after 14days of home use, giving Epi-E the maximum score of ' $5=$ Like a lot' in terms of overall liking (Table 5). When probed to explain why they liked Epi-E so much, women mentioned they "have begun to feel energy" and have gained "strength" from using it. Interviewers concurred, noting that all participants in both study periods seemed enthusiastic when discussing their experiences using Epi-E. Field notes from interviewers described the participants to be "very happy" and "satisfied", and "ready to continue" using it for a longer time period. When asked whether they would be willing to eat Epi-E again, 100\% of women replied affirmatively.

Willingness to pay data were collected from participants in September (non-Ramadan). Nearly all women (95.7\%) said they would purchase Epi-E if sold on the market. Women estimated that they would be willing to pay on average (SD) \$0.31 (0.29) per sachet, compared to $\$ 0.05(0.05)$, the average amount last paid for a daily

Table 4 Self-reported Epi-E consumption by participants during 2-week home trial period

\begin{tabular}{|c|c|c|}
\hline & June 2014 (Ramadan) & September 2014 (non-Ramadan) \\
\hline No. of participants, $(n)$ & 25 & 23 \\
\hline \multicolumn{3}{|l|}{ Sachet utilization at home during 2-week trial period } \\
\hline No. of sachets received at start of trial period, $(n)$ & 16 & 14 \\
\hline No. of total sachets consumed by participant, Mean (SD) & $14.0(0.3)$ & $14.0(0.2)$ \\
\hline No. of sachets consumed by participant per day, Mean (SD) & $1.7(0.5)$ & $1.1(0.3)$ \\
\hline No. of sachets consumed by others, Mean (SD) & $2.0(0.3)$ & $0.0(0.2)$ \\
\hline Any sachets sold or traded, $n(\%)$ & $0(0.0)$ & $0(0.0)$ \\
\hline \multicolumn{3}{|l|}{ Usual amount of Epi-E eaten each time consumed, $n(\%)$} \\
\hline Half sachet & $18(72.0)$ & $2(8.7)$ \\
\hline Full sachet & $7(28.0)$ & $20(87.0)$ \\
\hline More than a full sachet & $0(0.0)$ & $1(4.3)$ \\
\hline \multicolumn{3}{|l|}{ Time(s) of day consumed Epi-Ea,$n(\%)$} \\
\hline Morning & $21(84.0)$ & $18(60.0)$ \\
\hline Midday or Afternoon & $2(8.0)$ & $12(40.0)$ \\
\hline Dinner or Evening & $19(76.0)$ & $0(0.0)$ \\
\hline \multicolumn{3}{|l|}{ How usually consumed Epi-E, $n$ (\%) } \\
\hline Mixed with food & $1(4.0)$ & $0(0.0)$ \\
\hline Directly from sachet & $24(96.0)$ & $23(100.0)$ \\
\hline
\end{tabular}

${ }^{\text {aThe }}$ 'times of day consumed Epi-E' was calculated as the sum of total reported feeding episodes 
Table 5 Reported experience and willingness of participants to pay for Epi-E after 2-week home trial period

\begin{tabular}{|c|c|}
\hline & September 2014 (non-Ramadan) \\
\hline No. of participants, $(n)$ & 23 \\
\hline \multicolumn{2}{|l|}{ Hedonic scale scores of Epi-E ${ }^{a}$, median (min, max) } \\
\hline Overall liking & $5(5,5)$ \\
\hline Color & $5(5,5)$ \\
\hline Taste & $5(5,5)$ \\
\hline Smell & $5(5,5)$ \\
\hline \multicolumn{2}{|l|}{ Interviewer's perception, $n$ (\%) } \\
\hline Interviewer believes participant was enthusiastic about Epi-E & $23(100.0)$ \\
\hline Willingness to eat Epi-E again, $n(\%)$ & $23(100.0)$ \\
\hline Willingness to purchase Epi-E, $n(\%)$ & $22(95.70)$ \\
\hline \multicolumn{2}{|l|}{ Willingness to pay for Epi-E, Mean (SD) } \\
\hline Amount willing to pay per daily sachet of Epi- $E^{a}$ & $\$ 0.31(0.29)$ \\
\hline Amount last paid for daily prenatal micronutrient & $\$ 0.05(0.05)$ \\
\hline Amount last paid for 1 serving of favorite snack food & $\$ 0.31(0.19)$ \\
\hline Willing to pay more for Epi-E than prenatal micronutrient, $n(\%)$ & $23(100.0)$ \\
\hline Willing to pay more for Epi-E than favorite snack, $n(\%)$ & $15(65.21)$ \\
\hline
\end{tabular}

prenatal micronutrient supplement and \$0.31 (0.19), the average amount last paid for a serving of their favorite snack food.

\section{Discussion}

Using a two-part, multi-methods design, this study assessed the acceptability and utilization of a new formulation of LNS designed to meet the specific nutrient needs of pregnant women in rural Niger. Findings indicated very high acceptability among the study sample across two time periods. Participants rated Epi-E highly, with positive attitudes toward its organoleptic properties of color, taste, smell as well as an overall liking of the supplement, both immediately following two observed test meals but also after a 14-day home trial. Few side effects were reported, and women expressed an eagerness to continue to use Epi-E and a willingness to pay for it in the future. Acceptability was high in the Ramadan and non- Ramadan study periods, though we observed differing strategies for home utilization during the Ramadan holy month.

LNS has been reported to be highly acceptable for the prevention and treatment of undernutrition in children across various contexts [18, 20-22, 27-34]Ethnographic research using qualitative methods [22, 35-37] and 'willingness to pay' studies [38] similarly suggest high acceptability. The high acceptability recorded in this study is most consistent with experience using a 20-g LNS among pregnant and lactating women in Ghana [11]. In this similarly designed study, $64.0 \%$ (7/11) of participants gave the 20-g LNS an overall score of 5 ('Like a lot') after a 14-day home trial. LNS dose, micronutrient content, as well as social, cultural and economic characteristics of the study settings, however, differed.

Our study provides unique insights into LNS utilization in this population overall, and by time period. We found that participants made decisions about when to eat the supplement on an individual basis, determined by pragmatic household considerations and personal hunger cues that varied importantly by time period. In addition, while all participants were instructed to consume Epi-E as a home fortificant, mixed with local foods, participants preferred consuming Epi-E directly from the sachet. This utilization pattern differs from that found among pregnant women in Ghana, where nearly all participants (91.0\%) reported mixing the 20-g LNS with "porridge" (73.0\%) and "other foods besides porridge" (e.g., "soups, stews, bread, and other traditional dishes") [11] and from that found among pregnant and lactating women in Bangladesh, where $83-89 \%$ of women mixed the LNS with rice and other foods [39]. It is unclear why such different modes of utilization emerged between settings. However, it may be likely that the mode reported in our study stemmed from participant familiarity with PlumpyNut ${ }^{\oplus}$ a therapeutic product in the LNS family which is eaten directly from the sachet by malnourished children, and has been used in the Maradi region for over 10 years. It could be attributed to differences in the level of emphasis placed on compliance by study staff in each setting or differences in individual dietary rules or preferences of pregnant women between settings [40, 41]. Consumption direct from the sachet may also be a 
strategy to limit sharing in a context where food is traditionally shared within the household. When probed, our study participants explained that eating from the sachet just tasted better and was more convenient. Though not prescribed as per study protocol, we observed no adverse implications of this preferred, more convenient mode of utilization.

There are a number of strengths to this study. We first sought to understand acceptability from multiple angles and perspectives, considering the array of indicators to define and assess acceptability. By using both quantitative and qualitative data collection methods on the same topic, our study design included methodological triangulation. By investigating both the attitudes and behaviors of the participants themselves, as well as those reported by the interviewers, we were also able to corroborate findings among different participant types through participant triangulation $[26,42]$. The use of repeated observations of test meals on consecutive days reduced the likelihood of reactive behaviors from just a single observation period [43], while repeated observations of the home trial during non-Ramadan and Ramadan time periods provided a more comprehensive understanding of time-dependent dietary behaviors and their potential influence on LNS utilization. These strategies increase our confidence in the positive findings.

This study did have important limitations. First, the home-feeding trial was 14 days long and therefore findings may not reflect long-term acceptability. Ensuring sustained behavior change over time is a particularly difficult aspect of introducing new health practices and may be influenced by household-level utilization factors not assessed in this study [44]. High short-term acceptability observed in this study, however, was accompanied by very few adverse events, suggesting future compliance may be sustainable. High LNS acceptability has recently been shown to be sustained over longer time periods (e.g. up to 12 months) [45], and found to be associated with good adherence during community-based programming [46]. Second, social desirability to provide positive responses may have positively biased participant responses and interviewer field notes [47]. With this in mind, we built in multiple methods to assess LNS acceptability, including the repeated observations, the objective measures of timed and weighed test meals, and the multiple forms of triangulation. Third, the LNS testmeal amount was relatively small $(50 \mathrm{~g})$, although if the product were not acceptable based on flavor alone, then it should have been evident even with the small amount provided. Future studies may provide alternative preparations for testing (e.g. alone, mixed with maize meal, mixed with other local foods) to help identify preferences for the mode of utilization relevant for future public health programming. Fourth, the study did not assess participants' dietary intake or gestational age at enrollment, and did not conduct statistical testing for comparisons other than the primary aim. Finally, these results are context specific, specific to rural Niger where there is high seasonal food insecurity, limited social and economic development [48] and a beneficiary population that has had previous experience with other ready-touse foods. A relatively smaller sample size was deemed adequate in this specific, homogenous population.

In light of the potential for widespread use of LNS for the prevention and treatment of malnutrition in this setting, future studies are warranted to test and better understand acceptability. Studies among pregnant women with test-meals and home-feeding trials that are conducted over longer time periods, across different seasons, and during special time periods may yield more accurate estimates of acceptability and compliance. Future studies would benefit from data collection at the household-level, where less reactive behaviors may more likely be captured, and from longitudinal follow-up. Such findings are likely to provide a richer perspective of product acceptability and utilization. Larger study samples may also allow researchers to better explore differences in acceptability by participant type.

\section{Conclusions}

This study was the first to assess the acceptability and utilization of a $40 \mathrm{~g}$ LNS formulation among pregnant women in Niger. Despite its novel formulation designed to meet the nutrient needs of this vulnerable population with a dose nearly two times the typical given in other interventions, and with a higher-than-usual micronutrient profile, acceptability was high. The mode of utilization varied by household and individual considerations, but did not influence overall consumption. The Epi-E formulation will be tested as a potential strategy to improve the adequacy of nutrient intake and birth outcomes among pregnant women in this context.

\section{Abbreviations}

BRV-PV: Bovine rotavirus-pentavalent vaccine; IFA: Iron folic acid; LNS: Lipidbased nutrient supplement; MMN supplementation: Multiple micronutrient supplementation; RDA: Recommended daily allowance

\section{Acknowledgements}

Not applicable.

\section{Authors' contributions}

SI contributed to the conception and design of the study, collection, analysis and interpretation of data, and drafted the manuscript. SRK contributed to the analysis and interpretation of data, and helped draft the manuscript. AAM and OG contributed to data collection. MZ and RFG contributed to the conception and design of the study, as well as interpretation of final results. All authors critically reviewed the manuscript for important intellectual content and approved the final manuscript. SI is responsible for the final manuscript. 


\section{Funding}

This work was supported by Médecins Sans Frontières - Operational Center Geneva. The funder had no role in the study design, collection or analysis of data, writing of the report or the decision to submit the article for publication. Epicentre receives core funding from Médecins Sans Frontières.

\section{Availability of data and materials}

The datasets used during the current study are available from the corresponding author on reasonable request.

\section{Ethics approval and consent to participate}

This study was conducted according to the guidelines laid down in the Declaration of Helsinki and all procedures involving human subjects/patients were approved by the National Consultative Ethics Committee of Niger (Approval Number 018/2014/CCNE), as well as the Western Institutional Review Board (Protocol Number 20131413). Written informed consent was obtained from all participants.

\section{Consent for publication}

Not applicable.

\section{Competing interests}

Co-author "MZ" is employed by Nutriset. MZ had no role in data collection or statistical analysis of results.

\section{Author details}

${ }^{1}$ Epicentre, 8 rue Saint Sabin, 75011 Paris, France. ${ }^{2}$ Harvard T.H. Chan School of Public Health, 665 Huntington Ave, Boston, MA 02115, USA. ${ }^{3}$ Epicentre Niger, Quartier Plateau, Bd Maurice Delens Porte 206, 13330 Niamey, Niger. ${ }^{4}$ Nutriset SAS, Route du Bois Ricard, 76770 Malaunay, France.

Received: 19 January 2019 Accepted: 24 June 2019

Published online: 01 July 2019

\section{References}

1. Lee SE, Talegawkar SA, Merialdi M, Caulfield LE. Dietary intakes of women during pregnancy in low- and middle-income countries. Public Health Nutr. 2013;16(8):1340-53.

2. Black RE, Victora CG, Walker SP, Bhutta ZA, Christian P, de Onis M, Ezzati M, Grantham-McGregor S, Katz J, Martorell R, et al. Maternal and child undernutrition and overweight in low-income and middle-income countries. Lancet. 2013;382(9890):427-51.

3. Hoddinott J, Behrman JR, Maluccio JA, Melgar P, Quisumbing AR, RamirezZea M, Stein AD, Yount KM, Martorell R. Adult consequences of growth failure in early childhood. Am J Clin Nutr. 2013;98(5):1170-8.

4. McClure EM, Goldenberg RL, Dent AE, Meshnick SR. A systematic review of the impact of malaria prevention in pregnancy on low birth weight and maternal anemia. Int J Gynaecol Obstet. 2013;121(2):103-9.

5. Imdad A, Bhutta ZA. Intervention strategies to address multiple micronutrient deficiencies in pregnancy and early childhood. Nestle Nutr Inst Workshop Ser. 2012;70:61-73.

6. Pena-Rosas JP, Viteri FE. Effects and safety of preventive oral iron or iron+ folic acid supplementation for women during pregnancy. Cochrane Database Syst Rev. 2009;(4):CD004736.

7. Haider BA, Bhutta ZA. Multiple-micronutrient supplementation for women during pregnancy. Cochrane Database Syst Rev. 2012;11:CD004905.

8. Huybregts L, Roberfroid D, Lanou H, Menten J, Meda N, Van Camp J, Kolsteren P. Prenatal food supplementation fortified with multiple micronutrients increases birth length: a randomized controlled trial in rural Burkina Faso. Am J Clin Nutr. 2009;90(6):1593-600.

9. Mridha MK, Matias SL, Chaparro CM, Paul RR, Hussain S, Vosti SA, Harding KL, Cummins JR, Day LT, Saha SL, et al. Lipid-based nutrient supplements for pregnant women reduce newborn stunting in a cluster-randomized controlled effectiveness trial in Bangladesh. Am J Clin Nutr. 2016;103(1):236-49.

10. Dewey KG, Arimond M. Lipid-based nutrient supplements: how can they combat child malnutrition? PLoS Med. 2012;9(9):e1001314.

11. Adu-Afarwuah S, Lartey A, Zeilani M, Dewey KG. Acceptability of lipid-based nutrient supplements (LNS) among Ghanaian infants and pregnant or lactating women. Matern Child Nutr. 2011;7(4):344-56.
12. Ashorn $P$, Alho L, Ashorn U, Cheung YB, Dewey KG, Harjunmaa U, Lartey A, Nkhoma M, Phiri N, Phuka J, et al. The impact of lipid-based nutrient supplement provision to pregnant women on newborn size in rural Malawi: a randomized controlled trial. Am J Clin Nutr. 2015;101(2):387-97.

13. Isanaka S, Guindo O, Langendorf C, Matar Seck A, Plikaytis BD, SayinzogaMakombe N, McNeal MM, Meyer N, Adehossi E, Djibo A, et al. Efficacy of a low-cost, heat-stable Oral rotavirus vaccine in Niger. N Engl J Med. 2017; 376(12):1121-30.

14. Savy M, Edmond K, Fine PE, Hall A, Hennig BJ, Moore SE, Mulholland K, Schaible U, Prentice AM. Landscape analysis of interactions between nutrition and vaccine responses in children. J Nutr. 2009;139(11):2154S218S.

15. Scrimshaw NS, SanGiovanni JP. Synergism of nutrition, infection, and immunity: an overview. Am J Clin Nutr. 1997;66(2):464S-77S.

16. Moore SE, Jalil F, Ashraf R, Szu SC, Prentice AM, Hanson LA. Birth weight predicts response to vaccination in adults born in an urban slum in Lahore, Pakistan. Am J Clin Nutr. 2004;80(2):453-9.

17. Prentice $A M$, van der Merwe L. Impact of fatty acid status on immune function of children in low-income countries. Maternal \& child nutrition. 2011;7(Suppl 2):89-98.

18. Arimond M, Zeilani M, Jungjohann S, Brown KH, Ashorn P, Allen LH, Dewey KG. Considerations in developing lipid-based nutrient supplements for prevention of undernutrition: experience from the international lipid-based nutrient supplements (iLiNS) project. Matern Child Nutr. 2015;11(Suppl 4): 31-61.

19. UNICEF, WHO, UNU: Composition of a multi-micronutrient supplement to be used in pilot programmes among pregnant women in developing countries: report of a United Nations Children's fund (UNICEF), World Health Organization (WHO) and United Nations University workshop. In.; 1999.

20. Cohuet S, Marquer C, Shepherd S, Captier V, Langendorf C, Ale F, Phelan K, Manzo ML, Grais RF. Intra-household use and acceptability of ready-to-usesupplementary-foods distributed in Niger between July and December 2010. Appetite. 2012;59(3):698-705.

21. Hess SY, Bado L, Aaron GJ, Ouedraogo JB, Zeilani M, Brown KH. Acceptability of zinc-fortified, lipid-based nutrient supplements (LNS) prepared for young children in Burkina Faso. Matern Child Nutr. 2011;7(4): 357-67.

22. Ickes SB, Jilcott SB, Myhre JA, Adair LS, Thirumurthy H, Handa S, Bentley ME, Ammerman AS. Examination of facilitators and barriers to home-based supplemental feeding with ready-to-use food for underweight children in western Uganda. Matern Child Nutr. 2012;8(1):115-29.

23. Fleiss JL, Levin B, Paik MC. Statistical methods for rates and proportions. 3rd ed. Hoboken: John Wiley \& Sons; 2003.

24. Sandelowski M. Real qualitative researchers do not count: the use of numbers in qualitative research. Res Nurs Health. 2001;24(3):230-40.

25. Charmaz K. Constructing grounded theory: a practical guide through qualitative analysis. London: Sage Publications, Inc.; 2006.

26. Miles M, Huberman A. Qualitative data analysis. 2nd ed. Thousand Oaks, CA: Sage Publications, Inc.; 1994

27. Flax VL, Makinen S, Ashorn U, Cheung YB, Maleta K, Ashorn P, Bentley ME. Responsive feeding and child interest in food vary when rural Malawian children are fed lipid-based nutrient supplements or local complementary food. Matern Child Nutr. 2013:9(3):369-80.

28. Flax VL, Thakwalakwa C, Phuka J, Ashorn U, Cheung YB, Maleta K, Ashorn P. Malawian mothers' attitudes towards the use of two supplementary foods for moderately malnourished children. Appetite. 2009;53(2):195-202.

29. Iuel-Brockdorf AS, Draebel TA, Fabiansen C, Cichon B, Christensen VB, Yameogo C, Ritz C, Frahm Olsen M, Friis H. Acceptability of new formulations of corn-soy blends and lipid-based nutrient supplements in province du Passore, Burkina Faso. Appetite. 2015;91:278-86.

30. Matias SL, Chaparro CM, Perez-Exposito AB, Peerson J, Dewey K. Acceptability of a Lipid-Based Nutrient Supplement among Guatemalan Infants and Young Children. Washington, D.C: FANTA-2; 2011.

31. Olney D. Report of formative research conducted in Alta Verapaz, Guatemala, to help inform the health-strengthening activities and the social and behavior change communication strategy tha twill be implemented through the Mercy Corps PM2A Program-POCOMIDA. Washington, D.C.: FHI 360/FANTA-2 Bridge; 2012.

32. Parker ME, Bentley ME, Chasela C, Adair L, Piwoz EG, Jamieson DJ, Ellington S, Kayira D, Soko A, Mkhomawanthu C, et al. The acceptance and feasibility of replacement feeding at 6 months as an HIV prevention method in 
Lilongwe, Malawi: results from the BAN study. AIDS Educ Prev. 2011;23(3): 281-95.

33. Phuka J, Ashorn U, Ashorn P, Zeilani M, Cheung YB, Dewey KG, Manary M, Maleta K. Acceptability of three novel lipid-based nutrient supplements among Malawian infants and their caregivers. Matern Child Nutr. 2011;7(4): 368-77.

34. Rothman M, Berti C, Smuts CM, Faber M, Covic N. Acceptability of novel small-quantity lipid-based nutrient supplements for complementary feeding in a Peri-urban south African community. Food Nutr Bull. 2015;36(4):455-66.

35. Davis T, Fischer E, Rohloff $P$, Heimburger D. Chronic malnutrition, breastfeeding, and ready to use supplementary food in a Guatemalan Maya town. Hum Organ. 2014;73(1):72-81.

36. Kodish S, Aburto N, Dibari F, Brieger W, Agostinho SP, Gittelsohn J. Informing a behavior change communication strategy: formative research findings from the scaling up nutrition movement in Mozambique. Food Nutr Bull. 2015;36(3):354-70.

37. Kodish S, Aburto N, Hambayi MN, Kennedy C, Gittelsohn J. Identifying the sociocultural barriers and facilitating factors to nutrition-related behavior change: formative research for a stunting prevention program in Ntchisi, Malawi. Food Nutr Bull. 2015;36(2):138-53,

38. Vosti S, Adams K, Ayifah E, Guissou R, Hanjahanja-Phiri T, Ashorn P, Lartey A, Maleta K, Ouadraogo J, Dewey KG, et al. Willingness-to-pay for LNS products: evidence from the iLiNS studies. Eur J Nutr Food Saf. 2015;5(5): 1057-8.

39. Mridha M, Chaparro C, Matias S, Hussain S, Munira S, Saha S, Day L, Dewey KG. Acceptability of Lipid-Based Nutrient Supplements and Micronutrient Powders among Pregnant and Lactating Women and Infants and Young Children in Bangladesh and Their Perceptions about Malnutrition and Nutrient Supplements. Washington, D.C.: FHI 360/FANTA-2 Bridge; 2012.

40. Gittelsohn J, Vastine AE. Sociocultural and household factors impacting on the selection, allocation and consumption of animal source foods: current knowledge and application. J Nutr. 2003;133(11 Suppl 2):4036S-41S.

41. Wright L, Nancarrow C, Kwok P. Food taste preferences and cultural influences on consumption. Br Food J. 2001;103(5):348-57.

42. Lincoln YS, Guba EG. Naturalistic inquiry. Beverly Hills, CA: Sage Publications; 1985.

43. Gittelsohn J, Shankar A, West K, Ram R, Gnywali T. Estimating reactivity in direct observation studies of health behaviors. Hum Organ. 1997;56(2):182-9.

44. Prochaska JO, Redding CA, Harlow LL, Rossi JS, Velicer WF. The transtheoretical model of change and HIV prevention: a review. Health Educ Q. 1994:21(4):471-86.

45. Ashorn U, Alho L, Arimond M, Dewey KG, Maleta K, Phiri N, Phuka J, Vosti SA, Zeilani M, Ashorn P. Malawian mothers consider lipid-based nutrient supplements acceptable for children throughout a 1-year intervention, but deviation from user recommendations is common. J Nutr. 2015;145(7):1588-95.

46. Harding KL, Matias SL, Mridha MK, Moniruzzaman M, Vosti SA, Hussain S, Dewey KG, Stewart CP. Adherence to recommendations on lipid-based nutrient supplement and iron and folic acid tablet consumption among pregnant and lactating women participating in a community health programme in Northwest Bangladesh. Matern Child Nutr. 2017;13(1):e12252.

47. Fisher R. Social desirability bias and the validity of indirect questioning. J Consum Res. 1993;20(2):303-15.

48. Institut National de la Statistique, ICF International: Enquête Démographique et de Santé et à Indicateurs Multiples du Niger 2012. In. Calverton, Maryland USA; 2013.

\section{Publisher's Note}

Springer Nature remains neutral with regard to jurisdictional claims in published maps and institutional affiliations.

Ready to submit your research? Choose BMC and benefit from:
- fast, convenient online submission
- thorough peer review by experienced researchers in your field
- rapid publication on acceptance
- support for research data, including large and complex data types
- gold Open Access which fosters wider collaboration and increased citations
- maximum visibility for your research: over 100M website views per year
At BMC, research is always in progress.
Learn more biomedcentral.com/submissions

